\title{
Frequency regulation service of multiple-areas vehicle to grid application in hierarchical control architecture
}

\author{
Paramet Wirasanti, Suttichai Premrudeepreechacharn \\ Department of Electrical Engineering, Faculty of Engineering, Chiang Mai University, Thailand
}

\section{Article Info}

Article history:

Received Jun 17, 2020

Revised May 11, 2021

Accepted May 28, 2021

\section{Keywords:}

Adaptive droop control

Frequency regulation

Hierarchical control

Vehicle to grid

ABSTRACT

Regarding a potential of electric vehicles, it has been widely discussed that the electric vehicle can be participated in electricity ancillary services. Among the ancillary service products, the system frequency regulation is often considered. However, the participation in this service has to be conformed to the hierarchical frequency control architecture. Therefore, the vehicle to grid (V2G) application in this article is proposed in the term of multiple-areas of operation. The multiple-areas in this article are concerned as parking areas, which the parking areas can be implied as a V2G operator. From that, V2G operator can obtain the control signal from hierarchical control architecture for power sharing purpose. A power sharing concept between areas is fulfilled by a proposed adaptive droop factor based on battery state of charge and available capacity of parking area. A nonlinear multiplier factor is used for the droop adaptation. An available capacity is also applied as a limitation for the V2G operation. The available capacity is analyzed through a stochastic character. As the V2G application has to be cooperated with the hierarchical control functions, i.e. primary control and secondary control, then the effect of V2G on hierarchical control functions is investigated and discussed.
\end{abstract}

This is an open access article under the CC BY-SA license.

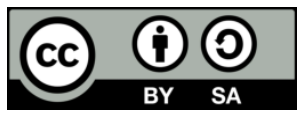

\section{Corresponding Author:}

Paramet Wirasanti

Department of Electrical Engineering

Chiang Mai University

239 Huay-Kaew Road, Suthep, Muang, Chiang Mai, 50200, Thailand

Email: paramet.w@cmu.ac.th

\section{INTRODUCTION}

Recently, the electric vehicles (EVs) are taking more market share in a light-vehicle transportation. It has been foreseen that the high capacity EV battery has a potential to participate and support power system operation [1], because most of the vehicle usage is in an idle state for a long parking period, e.g. during office hour or home parking [2]. This kind of behavior leads to a vehicle to grid (V2G) concept that the EVs can take the power from the grid or inject the power into the grid, while they are connected to the power grid.

To take an advantage of the V2G concept, the electricity ancillary services are widely discussed. The authors in [3]-[7] have been introduced that the EVs can participate in the following services, i.e. system regulation, peak shaving, reactive power compensation, and renewable energy support. Form the list of services, it shows that the V2G concept is able enter in a conventional service of transmission system operator (TSO) and in a smart grid oriented service for distribution system operator (DSO). The conventional frequency regulation service, Tenga et al. [8] and $\mathrm{Mu}$ et al. [9] has focused on a primary response of frequency regulation with the level of battery state of charge (SoC). Su et al. [10] and Falahi et al. [11] introduced voltage control via reactive power compensation from EVs in distribution system. Tomić and 
Kempton [12] has analyzed the economic of the V2G concept, when providing system regulation and peak shaving. Those mentioned study examples are based on the idea that the EVs are considered as an aggregated mobile energy storage model. Among variety services of the $\mathrm{V} 2 \mathrm{G}$ application, this paper has pointed out the frequency regulation service, because this service is related to power system stability and required more power than the service for DSO. Moreover, it has three time control interval, i.e. primary control, secondary control and tertiary control, that the EVs can be selected for the participation.

The recent studies of $\mathrm{V} 2 \mathrm{G}$ in the part of frequency regulation are more oriented to control architecture of load frequency control. The area control error (ACE) is also considered. Alhelou et al. [13] and Liu et al. [14] have structured the control area into two interconnected areas, which one area is equipped with the V2G. However, the EVs are considered as aggregated model. In the same way, Liu et al. [15] utilized two interconnected areas for the study. The stochastics behavior is included in this study. The idea of decentralized model of EVs model in the term of parking area is introduced in [16] and [17]. The potential capacity of each parking area is analyzed. The decentralized V2G system is also presented in [18]. The study focused on the information sharing between EV stations in order to design power sharing. This research work is studied based on a single ACE.

Bearing in mind that the connected location of EVs is spread out in distribution grid. Thus, this article is pointed out that the EVs model cannot be considered as a single aggregated model. Furthermore, the conformation with the frequency control architecture on TSO level has to be taken into account. Figure 1 shows an overview of proposed architecture. The complete control area consists of three levels [19]. The unit level is a generation unit, which primary control (PC) is equipped in every generation unit. The higher level is local level, the secondary control (SC) is located in this level. The highest level is the supervisory level or tertiary control level (TC). The reference signal is sent from the highest level to lower level. When the V2G application enters in the hierarchical control architecture, it is located at the unit level in distribution network. To equip with the power grid, there must exist a coupling factor similar to PC. In the case of EVs, the coupling factor needs to be driven from the grid side by frequency.

Regarding the coupling factor, a droop factor is generally used, and it has to be a function of SoC. In current researches, it found that there are two control strategies, i.e. the sectional control curve and the linear control curve. For the sectional control curve, [20] presented two difference droop factors for charging process and discharging process. Zhu et al. [21] has divided more section based on the idea of increasing flexibility. It has been shown that the sectional control curve satisfied the requirement under different circumstances, when the EVs is concerned as aggregated model. For the linear control curve, the key element in this strategy is the regulation- or multiple factor that is utilized for the adaptation based on SoC. Liu et al. [22] used a parabola function to define the relation between droop factor and SoC. Furthermore, the linear control curve can be a constant factor as in [23] and [24]. Both researches have used it in a combination with a scheduled charging power as an additional energy management. To conclude, the sectional control curve has an advantage according to flexibility. On the other hand, the droop adaptation of the linear control curve is simply adjusted by defining the function of multiple factor based on SoC. Note that the studies of droop factor of $\mathrm{V} 2 \mathrm{G}$ application are mostly aggregated EVs models.

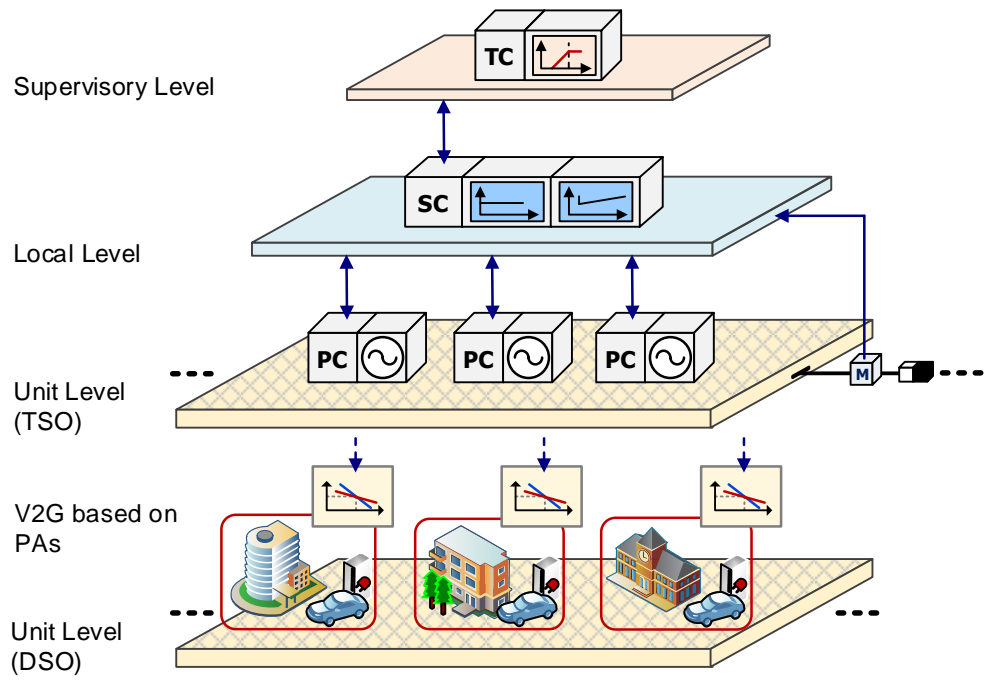

Figure 1. Hierarchical control architecture with multiple-areas of V2G 
According to proposed multiple-areas architecture in Figure 1, this paper is pointed out that the droop factor in each area has to be independence from each other. Thus, the conventional setting concept of droop factor is taken into account, which the setting is depended on the sizing of power plant [25]. Larger plant capacity has to be response more than smaller plant. On the same hand, this can be implied for the V2G application related to parking area. By this concept, the power sharing between parking areas is worthy for the investigation. The adaptation of droop factor is clearly based on battery SoC. The practical charging character is used to define the character of multiple factor, that there is a constant power period and slowly decreasing power period. In addition, the dead band and the relay function are implemented in V2G droop factor in order to assign the stop operation band and protect the oscillation at the transition point, respectively.

To summarize, the main contribution of this work are as follow:

- $\quad$ The structure of multiple-areas of V2G application in hierarchical control architecture

- The complete examination of the $\mathrm{V} 2 \mathrm{G}$ effect on the frequency regulation, i.e. primary control and secondary control

- $\quad$ The power sharing including the modelling of available capacity of each parking area

The paper is organized as follow: section 2 provides the structure of conventional hierarchical control and the V2G control in the part of frequency regulation. Section 3 explains the V2G operation and its mathematic description. Section 4 proposes the stochastic of parking area model and the calculation of estimated available capacity. Section 5 presents the implementation of proposed model in DIgSILENT Power Factory program and the validation of system frequency response. Section 6 presents two case studies, step response test and continuous test. The simulation results are discussed. Lastly, the conclusions are drawn.

\section{HIERARCHICAL CONTROL SCHEMATIC WITH V2G FUNCTION}

Understanding the V2G for frequency regulation service, the power system hierarchical control and the control strategy of EV have to be clarified. The control schematic of both functions in one control area is displayed in Figure 2, which is consisted of the primary control, the secondary control and the EV control. The primary frequency control is generally equipped with all generation unit. The primary control is in charge of stabilizing the power system frequency to a set value after disturbance or load change in the system. This function is performed by a coupling function, called droop factor. The droop factor has a responsibility to balance the injection power of the generator and load. It has to mention that the primary control function does not include the system frequency restoration to the reference values. To restore the frequency back to the nominal value, this action is done by to the secondary control. This process measures the system frequency and compares with the reference value. The frequency error is converted to the power via the droop factor. The output of the secondary control droop is regulated via PI controller and shared to the generation unit in order to adjust the power for the frequency regulation. In addition to the frequency service, the secondary control is also managed the power exchange between neighbor control areas.

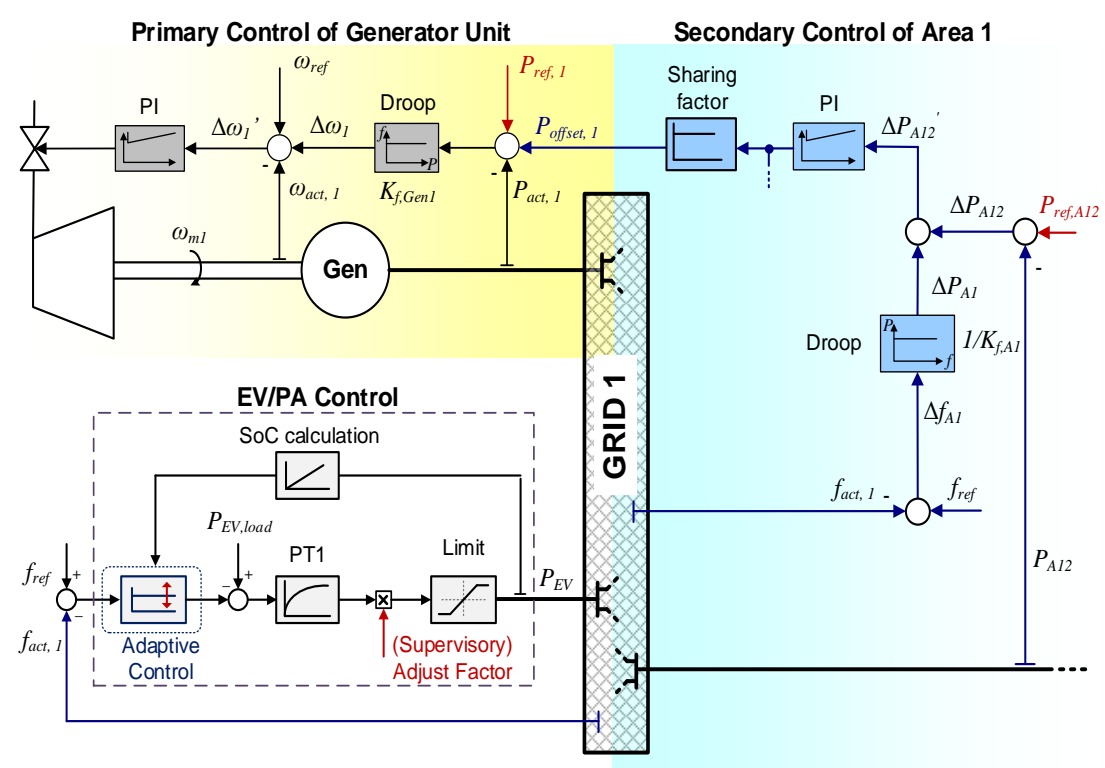

Figure 2. Hierarchical- and EV control block diagram for frequency regulation 
In a part of the EV control as frequency regulation service, the control block diagram is shown in Figure 2 as well. It is obvious that the cooperative with battery SoC is required. As noticed in Figure 2, the control is a function of battery SoC. This means that the charge/discharge rate of EV for frequency regulation is depended on SoC level. Further detail of this adaptive control block is provided in the section 3. Next, the first order characteristic (PT1) is implemented in order to describe the character of EV. Lastly, the limitation block is needed as a grid interface. It can be implied that the limitation block is a bidirectional inverter. To summarize, the EV can be directly joined the hierarchical control operation, which the V2G mode is operated as a support for frequency regulation.

\section{PORPOSED V2G OPERATION FUNCTION IN FREQUENCY REGULATION}

In this section, the function and mathematic description in EV model part is further discussed. In Figure 2, the main part of the EV model is an adaptive control block. The function of this block is to convert the frequency difference between grid frequency and reference frequency to an injected power or a consumed power in order to support the frequency regulation via a droop factor of $\mathrm{EV}\left(K_{E V}\right)$, which the $K_{E V}$ is a slope of regulation character. In addition, the dead band function is defined in the operation curve in order to set the zone that EV should not be active for frequency regulation [26]. The dead band is the frequency area between $\Delta f_{\text {Max }}$ and $\Delta f_{\text {Min }}$. The frequency dead band can be set according to the tolerance band, e.g. $\pm 1 \%$ of nominal frequency. The power regulation character is summarized as in Figure 3.

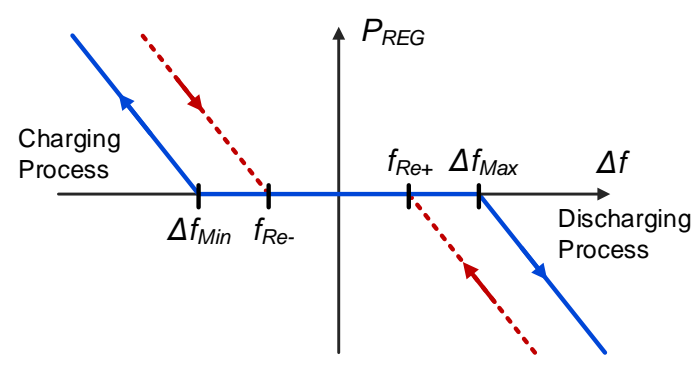

Figure 3. Character of V2G frequency regulation mode

To adapt the regulation character according to the battery SoC, the multiple factor $\left(m_{F}\right)$ is introduced. This factor is a number between 0 and 1 , which is a function of battery SoC. As a result, the mathematic description of $\mathrm{V} 2 \mathrm{G}$ regulation power $\left(P_{R E G}\right)$ is expressed in (1).

$$
\mathrm{P}_{R E G}= \begin{cases}-m_{F, D} \cdot K_{E V} \cdot \Delta f & ; \Delta f>\Delta f_{\text {Max }} \\ 0 & ; \Delta f_{\text {Min }}<\Delta f<\Delta f_{\text {Max }} \\ m_{F, C} \cdot K_{E V} \cdot \Delta f & ; \Delta f<\Delta f_{\text {Min }}\end{cases}
$$

The mathematic description of regulation power is divided in three parts. Having a look on control block in Figure 2, if the $\Delta f$ is positive and more than $\Delta f_{M a x}$, the regulation is in discharge process, which the power is negative. On the other hand, the regulation is in charge process, when $\Delta f$ is negative and less than $\Delta f_{\text {Min }}$, the power is then positive. In the dead band, the regulation is zero. The relay function is implemented in order to avoid the oscillation operation at the transition point. This relay function is a dash line in Figure 3.

As mentioned that the multiple function is designed for the adaptive purpose according to battery SoC. The original idea is referred to the normal charging process of battery that the charging current is constant, when the charging process is start. Later, when the battery is nearly full, the charging current is decreased until zero. Based on this information, the multiple factor characteristic curve is come out as in Figure 4.

The operation range of characteristic curve is defined by the $S o C_{M a x}$ and the $S o C_{M i n}$. In charging process, the multiple factor is kept constant at 1 from the $S o C_{M i n}$ to the turning point $\left(S o C_{T P}\right)$. When the SoC level reaches the turning point, the multiple factor is decreased until zero at the $S o C_{\text {Max }}$. For the discharging process, the multiple factor with the same character but on the opposite direction. To describe the characteristic curve, a quadratic equation is utilized. The mathematic formulation of multiple factor is written in (2). 


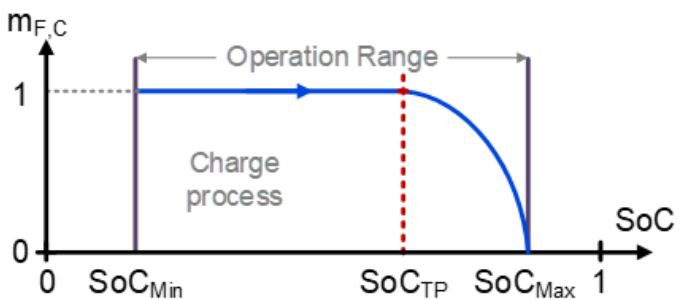

(a)

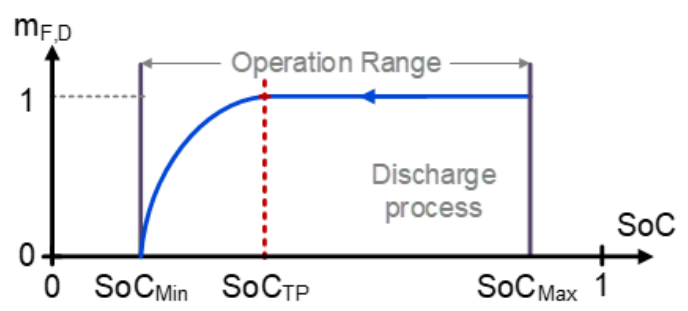

(b)

Figure 4. Multiple factor based on battery SoC; (a) charging process, (b) discharging process

$$
\begin{aligned}
& m_{F, C}=\left\{\begin{array}{cc}
1 & ; S o C_{M i n}<S o C<S o C_{T P} \\
-a_{C}\left(S o C-S o C_{T P}\right)^{2}+1 & ; S o C_{T P}<S o C<S o C_{M a x}
\end{array}\right. \\
& m_{F, D}=\left\{\begin{array}{cc}
1 & ; S o C_{T P}<S o C<S o C_{M a x} \\
-a_{D}\left(S o C_{T P}-S o C\right)^{2}+1 & ; S o C_{M i n}<S o C<S o C_{T P}
\end{array}\right.
\end{aligned}
$$

Where, $m_{F, C}$ and $m_{F, D}$ are the multiple factor of charging process and discharging process, respectively. The coefficient a is the function of $S o C_{T P}$ and $S o C$ level, which retunes the multiple factor to zero. As a result, the coefficient $a_{C}$ and $a_{D}$ are obtained as in (3).

$$
\begin{aligned}
& a_{C}=\frac{1}{\left(S o C_{M a x}-S o C_{T P}\right)^{2}} \\
& a_{D}=\frac{1}{\left(S o C_{T P}-S o C_{M i n}\right)^{2}}
\end{aligned}
$$

To summarize, the proposed active control methodology is functioned as a frequency regulation supporter. When the $\Delta f$ is in the operation range, the EV will charge/discharge the active power. The $K_{E V}$ is the main parameter for controlling charge/discharge rate. It can be implied that the $K_{E V}$ is a primary control of the EV. The $m_{F}$ is a factor, which adjusts the charge/discharge regarding the battery SoC level. Last but not least, the proposed methodology can be applied for a single EV model or an aggregated EV model.

\section{PARKING AREA MODEL AND ESTIMATED AVALIABLE CAPACITY}

As the grid connection of EVs are penetrated in distribution network, therefore, the authors have pointed out that the aggregation model of EVs should be based on parking area. The proposed parking area model is devolved based the arrival time and departure time of the EVs. Since the arrival time and departure time are randomly regarding the driver behavior, the Gaussian distribution is utilized to handle with this stochastic character [27]-[29]. The Gaussian distribution is a simple distribution, which fits many natural phenomenas. The arrival time and departure time of the EVs are adjusted through the mean value and the standard deviation value of distribution [30]. An example of parking area model input is given in Table 1. Four parking area types are presented. The office and the university type have mean value of arrival time and departure time. On the other hand, the supermarket and the department store have only the mean of arrival time. The idea behind this difference is that the office area or the university area have a regular office hour. So, it has to define arrival time and departure time. The standard deviation in this case is around 1. Meanwhile, the supermarket or the department store has a variety time range, then the one mean time with high standard deviation is enough.

Table 1. Example of parking area model input

\begin{tabular}{ccccc}
\hline Parking Area & Num. EVs & Mean Arr. time & Mean Dept. time & St. Dev. \\
\hline Office & 100 & 9 & 17 & 1 \\
University & 100 & 9 & 18 & 1.2 \\
Supermarket & 200 & 17 & - & 2.5 \\
Department store & 200 & 15 & - & 2.0 \\
\hline
\end{tabular}


The simulation result of parking area model is shown in Figure 5. The random function is used to generate the hourly arrival- or departure EVs. With this random number of EVs, the available capacity is able to be calculated. The general formulation of cumulative available capacity is described in (4).

$$
\begin{aligned}
& A C_{C}=\sum_{i=1}^{n}\left[\left(S o C_{\max }-S o C_{a r r i, i}\right) \times E V_{c a p, i}\right]-\sum_{i=1}^{m}\left[\left(S o C_{\max }-S o C_{d e p t, i}\right) \times E V_{c a p, i}\right] \\
& A C_{D}=\sum_{i=1}^{n}\left[\left(S o C_{\text {arrri }, i}-S o C_{\min }\right) \times E V_{\text {cap }, i}\right]-\sum_{i=1}^{m}\left[\left(S o C_{\text {dept }, i}-S o C_{\min }\right) \times E V_{c a p, i}\right]
\end{aligned}
$$

Where, $A C_{C}$ and $A C_{D}$ are the available capacity of charging process and discharging process, respectively. The $E V_{\text {cap }}$ is battery capacity of EV. The $S o C_{a r r i}$ and $S o C_{d e p t}$ are the battery state that arrives the parking area and leaves the parking area, respectively.
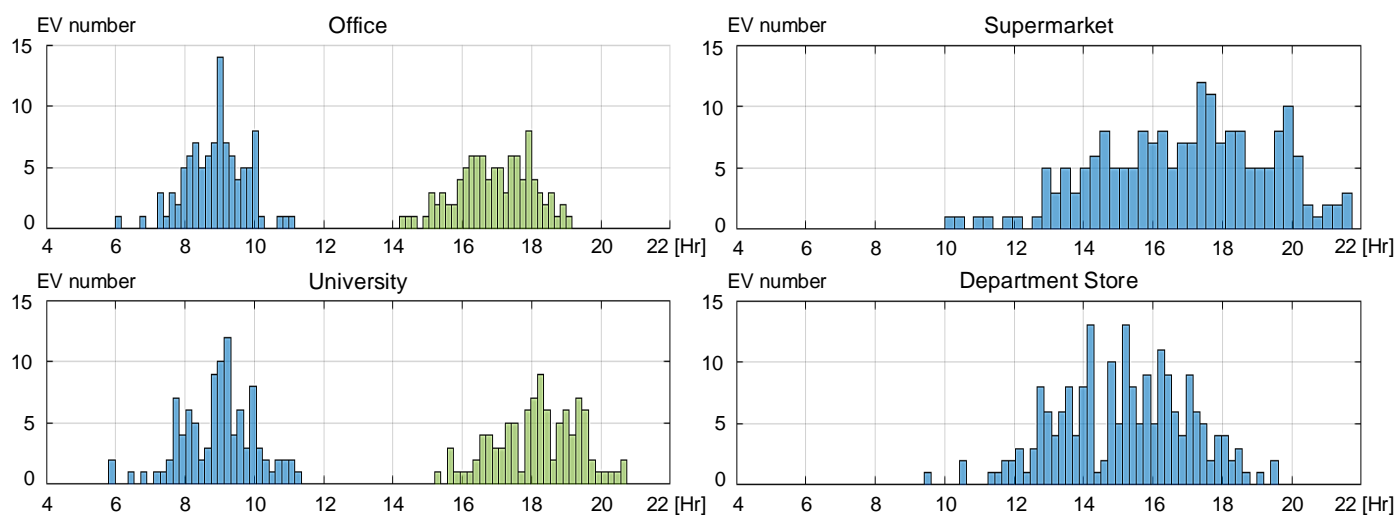

Figure 5. Result of parking area model

To demonstrate the available capacity regarding the result in Figure 5, the simplification is made by the following assumption. The $E V_{\text {cap }}$ of all EVs are constant at $50 \mathrm{kWh}$. The arrival of battery SoC is constant at 0.7 and the departure battery SoC is constant at 0.4 . The operation range of battery SoC for regulation process is between 0.9-0.3. The estimation of available capacity for charging process and discharging process is shown in Figure 6. The bar graph in Figure 6 stands for the capacity according to the number of EVs that arrive or depart parking area in hourly based on the result in Figure 5. For example, in the case of office parking area, it is defined with two characters, i.e. arrival and departure. When the EVs arrive parking area in the morning, the available capacity in charge- or discharge capacity is counted. When the EVs leave parking area, the capacity is withdraw from cumulative capacity. The cumulative available capacity can be calculated according to (5). In the case of supermarket, as the idea of this area is designed based on the high rate of arrival and departure, thus, the cumulative available capacity does not consider in this case. The bar graph is hourly considered as the available capacity in this parking area type.
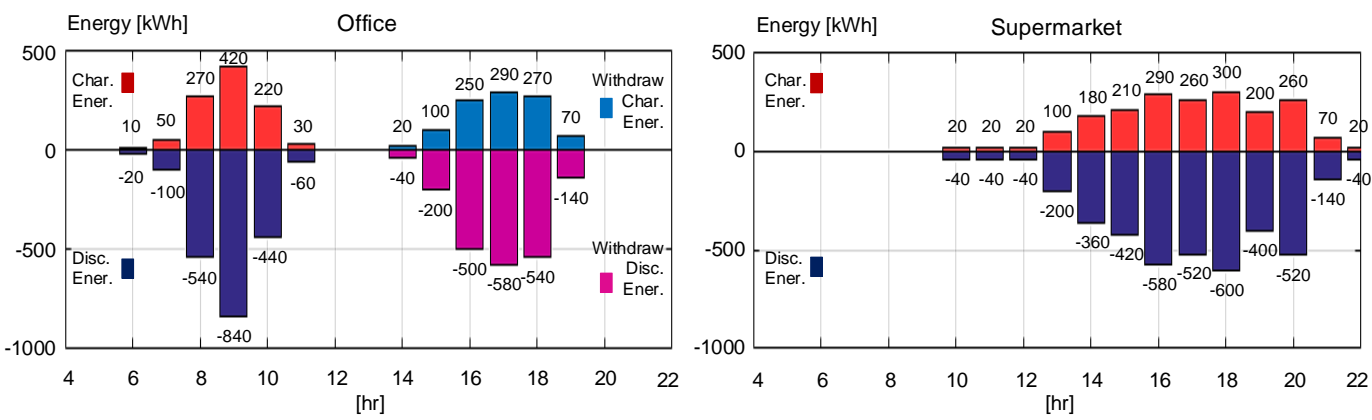

Figure 6. Estimated charge- and discharge available capacity 
To recapitulate, the Gaussian distribution is used for the parking area model. The number of EV, mean value of arrival time or departure time and standard deviation are required. Two parking area models are defined. The first is the area that has regular office hour and long parking period. The cumulative available capacity is subsequently applied in this case. The second is the area that has variety time range and high rate of arrival and departure. In this case, the available capacity is hourly considered. Note that, calculated available capacity is the estimation value based on the stochastic character. This available capacity is a kind of reserve power for each parking area.

\section{MODEL IMPLEMENTATION AND FREQUENCY RESPONSE VALIDATION}

To simulate and evaluate the proposed hierarchical- and EV control block diagram for frequency regulation, the DIgSILENT simulation language (DSL) in PowerFactory program is considered as a simulation platform. The DSL can represent the dynamic of power system simulation based on the root mean square value. As a result, the model of EV and power system according to Figure 2 are implemented based on DSL. The first step of EV modelling is to select the component that can provide the active power in both directions according to the behaviors of $\mathrm{V} 2 \mathrm{G}$ process. A static generator is considered and picked up as an interface element between power network and the proposed control strategy. Figure 7 shows the control frame of V2G model in DSL. The proposed mathematic description of V2G operation function in section 4 is programmed in the "Pcontrol block". The "PTl block" is used for describing the behavior of converter. The "Phase Lock Loop block" provides the reference angle for the static generator. Note that the "iq_ref" of static generator is left as an open input port because the active power is only considered in this study. The "Battery block" is in charge for battery SoC calculation based on the concept of active power integration.

To study the frequency regulation, it is important to chek frequency response. The power system unit in this research work is applied by a synchronous generator model, which is available in DIgSILENT library. The governor droop factor is adjusted to examine the primary respose. In addition, the secondary control block is added. The PI controller is fine-tuned to assure the secondary respose. To test the response, two step load events, i.e. increasing load $0.1 \mathrm{pu}$. at $100 \mathrm{~s}$ and decreasing load $0.1 \mathrm{pu}$. at $1100 \mathrm{~s}$, are used. The result is shown in Figure 8, which the frequency response looks proper. When the character of primary control is observed, it can be noticed from the result that the duration time of primary control action is around $72 \mathrm{~s}$. The frequency drop is around $2 \%$. The recovery time of frequency according to the secondary control is around $728 \mathrm{~s}$ or $12.2 \mathrm{~min}$. Form the operation time of the primary control and the secondary control, both follow the standard of hierarchical control strategy [20].

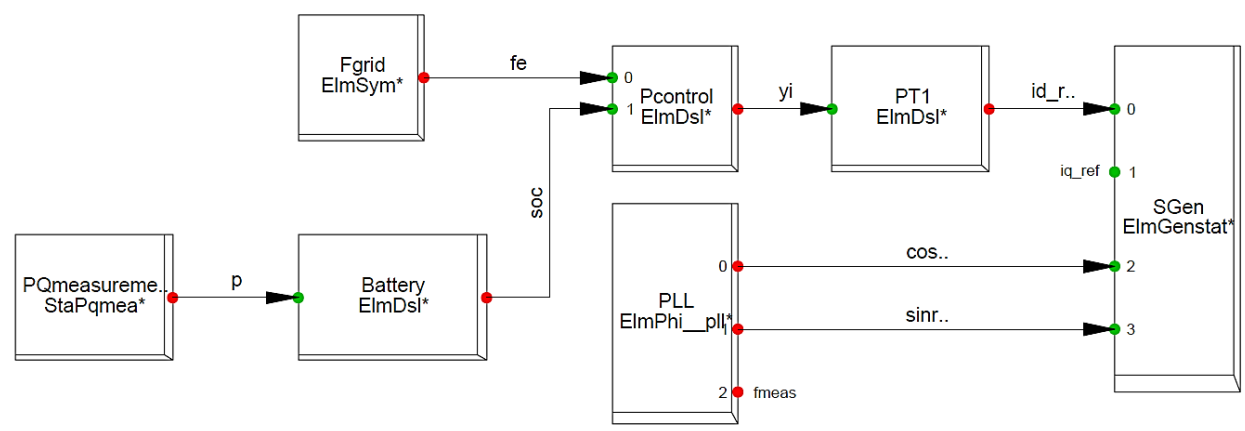

Figure 7. V2G control frame in DSL

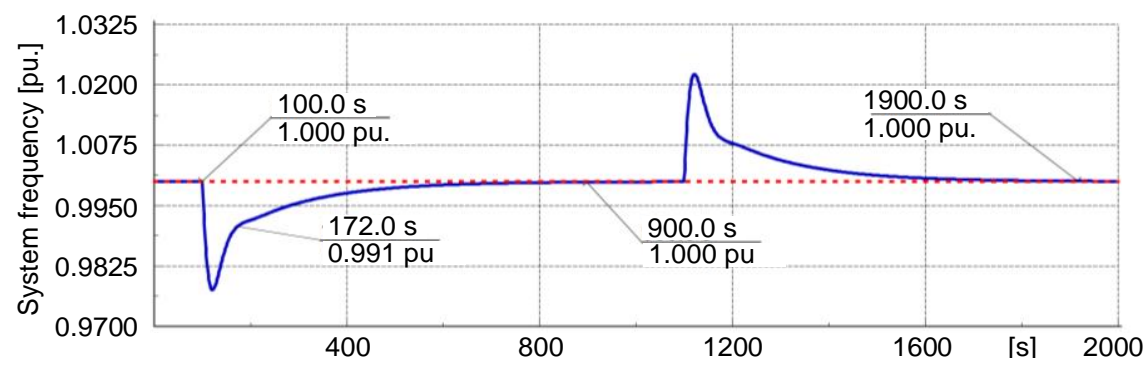

Figure 8. Response of power system frequency 


\section{CASE STUDIES AND DISCUSSION}

To study the frequency regulation when the proposed $V 2 G$ operation is a part of hierarchical control, two case studies are developed. The first case is the step response test. This case is designed for the study of V2G effect on the primary control and the secondary control. Moreover, this case is a validation case for the proposed strategy, which the multiple factor and power sharing are the main examination. The second case is the continuous test, which means that the $\mathrm{V} 2 \mathrm{G}$ operation is investigated along the load profile in one day. The stochastic of parking area model and the available capacity are considered in this study. Since, the target of both studies is the operation function test, thus the simple test system in Figure 9 is sufficient. The system load model is depended on the case studies, the case study 1 is a spot load and the case study 2 is a load profile. The system bases are set as follow: $S_{\text {Base }}$ is equal to $10 \mathrm{MVA}, V_{\text {Base }}$ is $22 \mathrm{kV}$, and $f_{\text {Base }}$ is $50 \mathrm{~Hz}$.

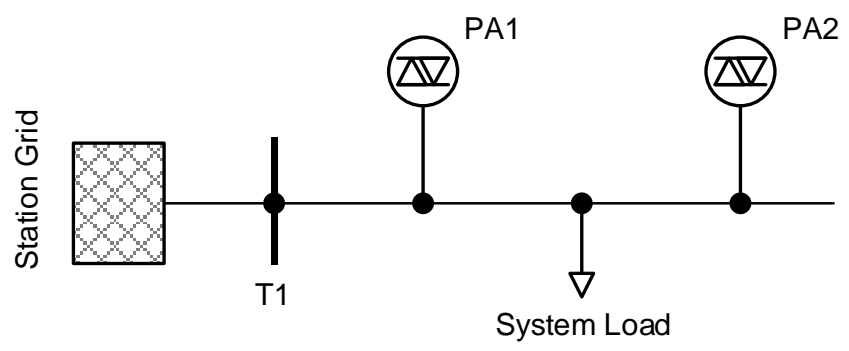

Figure 9. Test system for case studies

The two PA models are designed with difference assumptions. It is assumed that the PA1 has larger parking capacity than PA2. As a consequence, the droop factor of PA1 should be higher than the droop factor of PA2. This means that the PA1 should delivered more power than PA2. To check the function of multiple factor, the SoC level of PA2 is set to lower than the turning point. The frequency dead bands for relay function are set to $\pm 0.01 \mathrm{pu}$. and $\pm 0.005 \mathrm{pu}$. The PA's parameters are shown in Table 2 .

Table 2. Parameters of parking area

\begin{tabular}{ccc}
\hline Parameters & PA1 & PA2 \\
\hline Initial SoC & 0.7 & 0.5 \\
So $C_{\text {Max }} / S o C_{M i n}$ & $1 / 0.3$ & $1 / 0.3$ \\
So $C_{T P, C} /$ So $C_{T P, D}$ & $0.8 / 0.6$ & $0.8 / 0.6$ \\
Droop factor & 4 & 2 \\
$f_{M a x} / f_{\text {Min }}$ & $1.01 / 0.99 \mathrm{pu}$. & $1.01 / 0.99 \mathrm{pu}$. \\
$f_{R e+} / f_{R e-}$ & $1.005 / 0.995 \mathrm{pu}$. & $1.005 / 0.995 \mathrm{pu}$. \\
\hline
\end{tabular}

\subsection{Case study 1-Step response test}

The objectives of step response test are the study of primary control and secondary control under frequency regulation service and the validation of proposed V $2 \mathrm{G}$ operation. From the introduced test system, the $0.05 \mathrm{pu}$. step load is applied at $100 \mathrm{~s}$. The simulation results, i.e. the frequency response, the active power of parking areas and the multiple factor of parking areas, are discussed as follow.

Having a look on a comparative system frequency responses in Figure 10(a), there is a different during the primary control period and the secondary control period. In the primary control period, the EVs are activated as V2G when the frequency is dropped to their operation range. According to this fact, there is a small delay in delivering the power from PAs, see Figure 10(b). This means that the V2G operation is not a typical primary control, but it functions as a supporter. Regarding the frequency response in this period, the response is surely faster than the system, which does not have the support from V2G.

To bring the frequency back to the nominal value in the secondary control part, the EVs also support this working process until the frequency is back to $f_{R E}$. In Figure $10(\mathrm{~b})$, the active power from PAs is continually supplied by the system. But the supplied power is slowly decreased according to the increasing of frequency. In the same time, the generation power from the main grid is increased in order to cover the load change. At $875 \mathrm{~s}$, the system frequency is back to $f_{R E}$, but the delivered power from PAs is not immediately stopped. This is the proposed relay function. The support power in the secondary control process effects directly on the frequency response. The frequency response of the system that has a support from EVs is slower than the normal system. The cause of this point is that the main system delivers less power, then the 
frequency recovery is accordingly slower. In summary of the primary control and the secondary control under frequency regulation service, the $\mathrm{V} 2 \mathrm{G}$ operation works as a support in frequency regulation. It helps system frequency in fast response during primary control process, but the frequency response is slightly slowdown in secondary control process.

Next, the proposed V2G operation is examined. The main point in this part is the power sharing between PAs and the multiple factor of each area. The consideration of this part is the delivered active power in Figure 10(b) and the multiple factor of PA. Having a look on the highest delivered power, the active power of PA1 is around $0.022 \mathrm{pu}$ and the active power of PA2 is around $0.01 \mathrm{pu}$. As the droop factor of PA1 is a double value of PA2, then the power from PA1 should be two times more than PA1. However, there is a slightly difference around $0.02 \mathrm{pu}$. This difference is the effect of multiple factor, see Figures 10(d) and 10(f). The multiple factor of PA1 is equal to 1, while the multiple factor of PA2 is less than 1 . This is the cause of SoC level. Since the SoC level of PA2 is less than the turning point, then the multiple factor is a parabola function, see Figure 3. Let's check the SoC level of PAs after the frequency regulation service, see Figures 10(c) and 10(e). The change of SoC level is correct, as the change of PA1 is around two times more than PA2. Remark, the capacity of both PAs in this study are equal. Up to this point, the study of step response confirms that the mathematics function of proposed strategy works correctly.

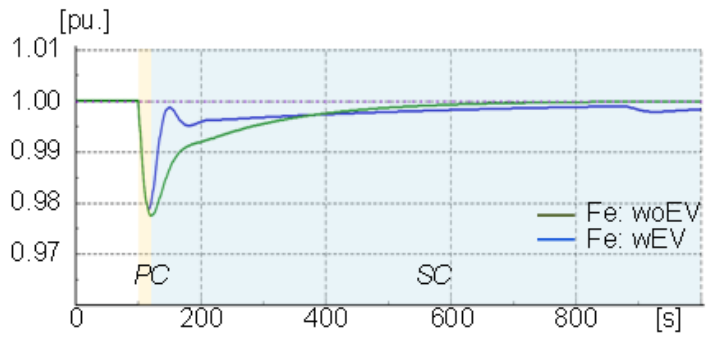

(a)

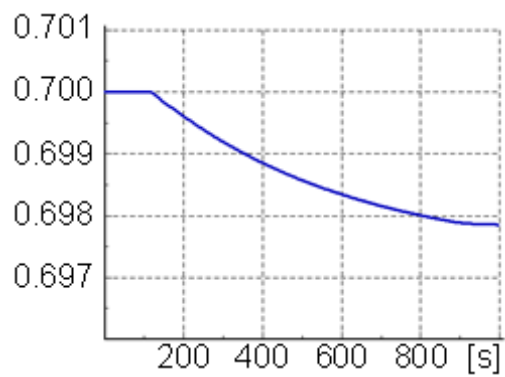

(c)

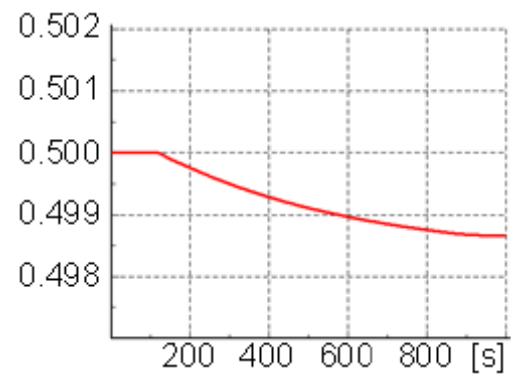

(e)

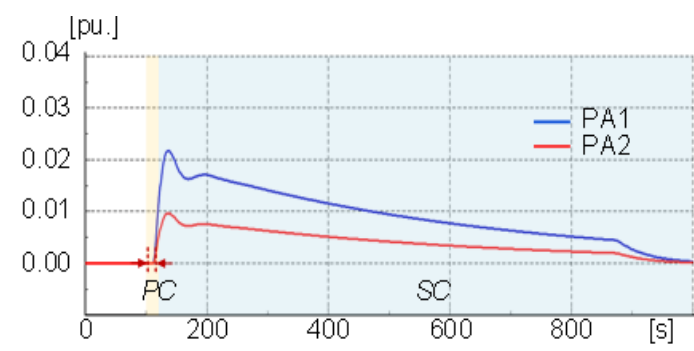

(b)

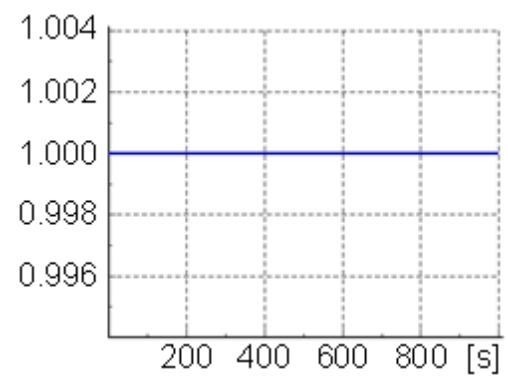

(d)

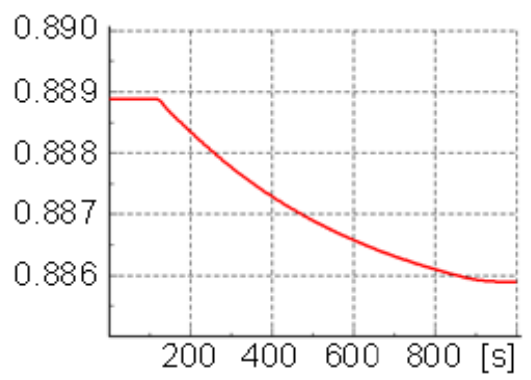

(f)

Figure 10. Simulation results; (a) power system frequency response, (b) active power from parking areas (c) SoC of PA1, (d) multiple factor of PA1, (e) SoC of PA2 and (f) multiple factor of PA2

\subsection{Case study 2 -continuous test}

In continuous study, the $\mathrm{V} 2 \mathrm{G}$ action in daily operation is the main investigation. The estimated available capacity of parking area is taken into account. The estimated available capacity office area and the supermarket in Figure 6 is applied. The estimated available capacity is implemented as a limitation in V2G 
control frame. The set parameters of office area and the supermarket area are referred to PA1 and PA2 in Table 2, respectively. The standard load profile of general commercial area [31] is selected for the study.

At the first step of the continuous test, the V2G operation is observed. When there is no system event in the system, the V2G is not active, see a dash line in Figure 11(a). Because the process of secondary control brings the system frequency back to rated value, the frequency is not enter into the operation range of $\mathrm{V} 2 \mathrm{G}$ process. This scenario also supports the result in the case study1 that the benefit of V2G operation is mainly on the primary process. Next, the system events are created in order to investigate V2G action in daily operation and available capacity of parking area. Two system events are assumed. The $0.1 \mathrm{pu}$. load is added to the grid at $10 \mathrm{a} . \mathrm{m}$., and this amount of load is removed from the grid at $2 \mathrm{p} . \mathrm{m}$. This event can be referred to a lockout of small generation unit due to a fault. Figure 11(b) shows the action of V2G process. It is obvious that the PAs inject the power into the network during event 1 and consume the power during event 2.

The zoom display of active power and energy of both PAs during event 1 and event 2 are shown in Figures 11(c)-11(f). Having a look on the injection power during event1, the PA1 delivers more power than PA2 according to the SoC level. However, the interesting point is that the PA2 has reached limitation regarding the available capacity. Then, the delivered power from PA2 is stopped. This can be easily noticed by response in Figure 11(d) that the used energy level of PA2 enters the steady state faster than PA1. In the part of event2, the response of PA1 and PA2 become similar, see Figure 11(f). This means that the available capacity of both PAs is enough for the operation. Considering the amount of energy of both PAs during V2G process, $100 \mathrm{kWh}$ is used during event 1 and $120 \mathrm{kWh}$ during event2. Comparing this amount of energy to available capacity in Figure 6, it still has an energy gap that the EVs can support frequency regulation. To this point, it has to mention that the energy usage depends on the level of power system event and the setting of droop factor in each PA.

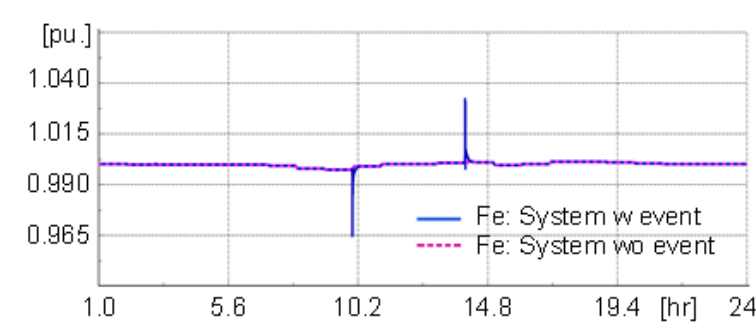

(a)

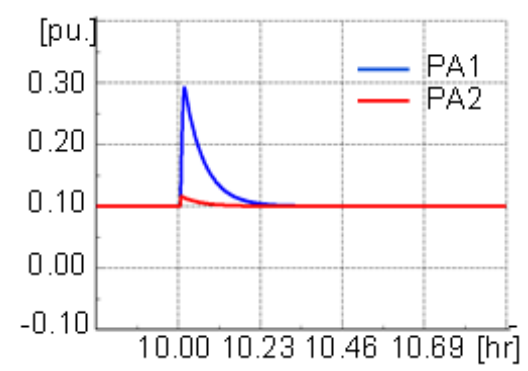

(c)

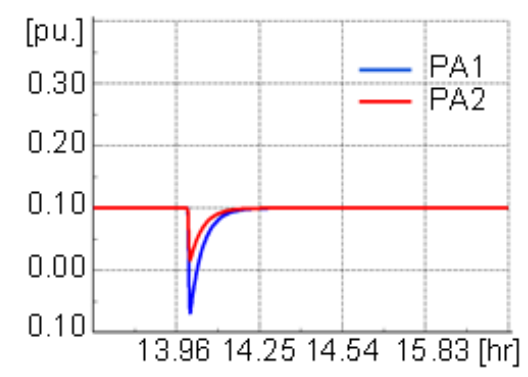

(e)

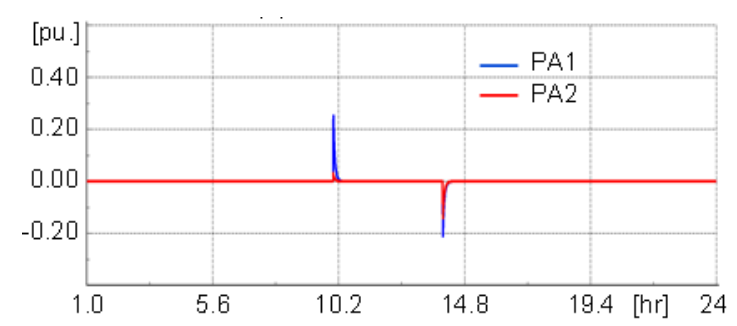

(b)

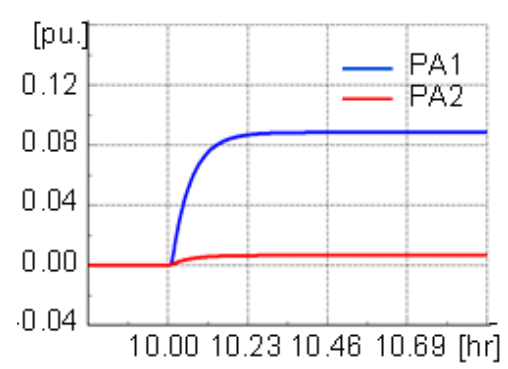

(d)

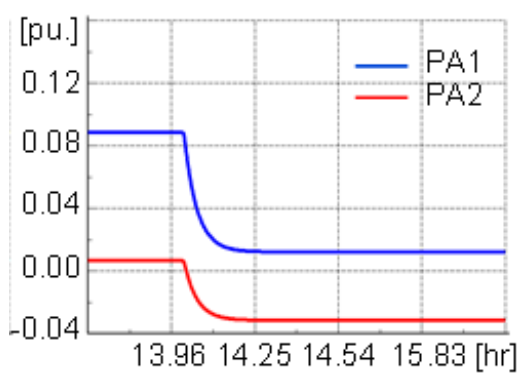

(f)

Figure 11. Simulation results; (a) system frequency, (b) active power from parking areas, (c) active power event 1, (d) energy event 1, (e) active power event 2 and (f) energy event 2 
To conclude, this study case confirm that V2G operation is only active when there is a power system event. Because in normal operation, the frequency is kept to rated value by secondary control process. This emphasizes that the V2G operation is a supporter for frequency regulation. Since the power system event may not happen every day, the available capacity can be considered as power system reserve.

\section{CONCLUSION}

The integration of V2G application in hierarchical control architecture has been researched in the part of frequency regulation. The research focus is how the $\mathrm{V} 2 \mathrm{G}$ in distribution level effects the convention control in transmission system level. Furthermore, this work pointed out that the EVs cannot be considered as one single group of $\mathrm{V} 2 \mathrm{G}$ operation, but it has to be operated as multiple-areas of $\mathrm{V} 2 \mathrm{G}$ and related to the location in distribution network. Achieving the aim of this study, the V2G model is developed. The model consists of two main parts, i.e. the power regulation part and the estimated available capacity part. In the part of power regulation, the EV droop control function is proposed. The droop is developed based on the nonlinear function of multiple factor and battery SoC level. In the part of estimated available capacity, the Gaussian distribution is used. The number of EV, the mean of arrival time, the mean of departure time, and standard deviation of each parking areas are the input for the calculation of available capacity.

To demonstrate multiple-areas of V2G operation in hierarchical control architecture, two simulation case studies, i.e. the step response test and the continuous test, are introduced. The proposed V2G control function and the power sharing between parking areas with the limitation of available capacity have been proved by these tests. In addition, it was found that the V2G operation effected the primary control period more than the secondary control period. As its control strategy can conform the hierarchical control architecture. The V2G application can be considered as power system reserve.

\section{ACKNOWLEDGEMENTS}

This research was supported by the Office of the Higher Education Commission and the Thailand Research Fund (Grant No. MRG6180068).

\section{REFERENCES}

[1] P. Cazzola et al., "Global EV Outlook 2018: Towards cross-modal electrification," International Energy Agency, pp. 1-141, 2018, doi: 10.1787/9789264302365-en.

[2] C. Lee and C. Wu, "Learning To Recognize Driving Patterns For Collectively Characterizing Electric Vehicle Driving Behaviors," International Journal of Automotive Technology, vol. 20, no. 6, pp. 1263-1276, 2019, doi: 10.1007/s12239-019-0118-4.

[3] K. Hedegaard, H. Ravn, N. Juul, P. Meibom, "Effects of electric vehicles on power systems in Northern Europe," Energy, vol. 48, no. 1, pp. 356-368, 2012, doi: 10.1016/j.energy.2012.06.012.

[4] S. Sarabi, A. Bouallaga, A. Davigny, B. Robyns, V. Courtecuiss, Y. Riffonneau et al., "The feasibility of the ancillary services for Vehicle-to-grid technology," IEEE International Conference on the European Energy Market, 2014, pp. 1-5, doi: 10.1109/EEM.2014.6861251.

[5] C. Li, Y. Cao, Y. Kuang, B. Zhou, "Influences of Electric Vehicles on Power System and Key Technologies of Vehicle-to-Grid," Springer-Verlag Berlin Heidelberg, 2016, doi: 10.1007/978-3-662-49364-9.

[6] K. Knezović, Sergejus Martinenas, Peter Bach Andersen, Antonio Zecchino, Mattia Marinelli, "Enhancing the Role of Electric Vehicles in the Power Grid: Field Validation of Multiple Ancillary Services," IEEE Transactions on Transportation Electrification, vol. 3, no. 1, pp. 201-209, 2017, doi: 10.1109/TTE.2016.2616864.

[7] J. M. Clairand, "Participation of Electric Vehicle Aggregators in Ancillary Services Considering Users' Preferences," Sustainability, vol. 12, no. 1, pp. 1-17, 2020, Art. no. 8, doi: 10.3390/su12010008.

[8] F. Tenga, Y. Mu, H. Jia, J. Wu, P. Zeng, G. Strbac, "Challenges of Primary Frequency Control and Benefits of Primary Frequency Response Support from Electric Vehicles," Energy Procedia, vol. 8, pp. 985-990, 2016, doi: 10.1016/j.egypro.2016.06.123.

[9] Y. Mu, J. Wu, J. Ekanayake, N. Jenkins, H. Jia, "Primary Frequency Response From Electric Vehicles in the Great Britain Power System," IEEE Transactions on Smart Grid, vol. 4, no. 2, pp. 1142-1150, 2013, doi: 10.1109/TSG.2012.2220867.

[10] S. Su, Y. Hu, S. Wang, W. Wang, Y. Ota, K. Yamashita et al., "Reactive power compensation using electric vehicles considering drivers' reasons," IET Generation, Transmission \& Distribution, vol. 12, no. 20, pp. 4407-4418, 2018, doi: 10.1049/iet-gtd.2017.1114

[11] M. Falahi, H.-M. Chou, M. Ehsani, Le Xie, K. L. Butler-Purry, "Potential Power Quality Benefits of Electric Vehicles," IEEE Transactions on sustainable energy, vol. 4, no. 4, pp. 1016-1023, 2013, doi: 10.1109/TSTE.2013.2263848.

[12] J. Tomić and W. Kempton, "Using fleets of electric-drive vehicles for grid support," Journal of Power Sources, vol. 168, no. 2, pp. 459-468, 2007, doi: 10.1016/j.jpowsour.2007.03.010. 
[13] H. Alhelou, P. Siano, M. Tipaldi, R. Iervolino, F. Mahfoud, "Primary Frequency Response Improvement in Interconnected Power Systems Using Electric Vehicle Virtual Power Plants," World Electric Vehicle Journal, vol. 11, no. 2, pp. 1-13, 2020, Art. no. 40, doi: 10.3390/wevj11020040.

[14] H. Liu, Z. Hu, Y. Song, J. Wang, X. Xie, "Vehicle-to-Grid Control for Supplementary Frequency Regulation Considering Charging Demands," IEEE Transactions on power systems, vol. 30, no. 6, pp. 3110-3119, 2015, doi: 10.1109/TPWRS.2014.2382979.

[15] H. Liu, K. Huang, Y. Yang, H. Wei, S. Ma, "Real-time vehicle-to-grid control for frequency regulation with high frequency regulating signal," Protection and Control of Modern Power Systems, vol. 3, pp. 1-8, 2018, Art. no. 13, doi: 10.1186/s41601-018-0085-1.

[16] R. Pagany, A. Marquardt, R. Zink, "Electric Charging Demand Location Model-A User and Destination-Based Locating Approach for Electric Vehicle Charging Stations," Sustainability, vol. 11, no. 8, pp. 1-15, 2019, doi: $10.3390 / \mathrm{su} 11082301$.

[17] G. Graber, Fr.Lamberti, V. Calderaro, V. Galdi, A. Piccolo, "Stochastic characterization of V2G parking areas for the provision of ancillary services," 2017 IEEE PES Innovative Smart Grid Technologies Conference Europe (ISGT-Europe), 2017, pp.1-6, doi: 10.1109/ISGTEurope.2017.8260256.

[18] D. Orihara, S. Kimura, H. Saitoh, "Frequency Regulation by Decentralized V2G Control with Consensus-Based SOC Synchronization," IFAC-PapersOnLine, vol. 51, no. 28, pp. 604-609, 2018, doi: 10.1016/j.ifacol.2018.11.770.

[19] Y. Han, H. Li, P. Shen, E. A. A. Coelho, J. M. Guerrero, "Review of Active and Reactive Power Sharing Strategies in Hierarchical Controlled Microgrids," IEEE Transactions on Power Electronics, vol. 32, no. 3, pp. 2427-2451, 2017, doi: 10.1109/TPEL.2016.2569597.

[20] R. Wei, Z. Liu, Ke Zhou, L. Xu, B. Xu, "Frequency control in distribution feeders based on bidirectional V2G converter for EV," I2017 IEEE Conference on Energy Internet and Energy System Integration (EI2), 2017, pp. 1-5, doi: 10.1109/EI2.2017.8245242.

[21] X. Zhu, M. Xiaa, H.-Dong Chiang, "Coordinated sectional droop charging control for EV aggregator enhancing frequency stability of microgrid with high penetration of renewable energy sources," Applied Energy, vol. 210, pp. 936-943, 2018, doi: 10.1016/j.apenergy.2017.07.087.

[22] H. Liu, Z. Hu, Y. Song, J. Lin, "Decentralized Vehicle-to-Grid Control for Primary Frequency Regulation Considering Charging Demands," IEEE Transactions on Power Systems, vol. 28, no. 3, pp. 3480-3489, 2013, doi: 10.1109/TPWRS.2013.2252029.

[23] N. Neofytou, K. Blazakis, Y. Katsigiannis, G. Stavrakakis, "Modeling Vehicles to Grid as a Source of Distributed Frequency Regulation in Isolated Grids with Significant RES Penetration,” Energies, vol. 12, no. 4, 2019, Art. no. 720, doi: 10.3390/en12040720.

[24] H. Liu, J. Qi, J. Wang; P. Li, C. Li, H. Wei, "EV Dispatch Control for Supplementary Frequency Regulation Considering the Expectation of EV Owners," IEEE Transactions on Smart Grid, vol. 9, no. 4, pp. 3763-3772, 2018, doi: 10.1109/TSG.2016.2641481.

[25] Fahmilia and E. Leksonob, "The New Method to Determine the Value of Speed Droop for Subcritical Coal Fire Power Plant in Order to Contribute to Primary Frequency Control of Power System," Procedia Engineering, vol. 170, pp. 496-502, 2017, doi: 10.1016/j.proeng.2017.03.079.

[26] J. A. P. Lopes, F. J. Soares, P. M. Rocha Almeida, "Integration of Electric Vehicles in the Electric Power System," Proceedings of the IEEE, vol. 99, no. 1, pp. 168-183, 2011, doi: 10.1109/JPROC.2010.2066250.

[27] J. Dong and Z. Lin, "Stochastic Modeling of Battery Electric Vehicle Driver Behavior: Impact of Charging Infrastructure Deployment on the Feasibility of Battery Electric Vehicles," Journal of the Transportation Research Board, vol. 2454, no. 1, pp. 61-67, 2014, doi: 10.3141/2454-08.

[28] P. Sokorai, A. Fleischhacker, G. Lettner, H. Auer, "Stochastic Modeling of the Charging Behavior of Electromobility," World Electric Vehicle Journal, vol. 9, no. 3, pp. 1-14, 2018, Art. no. 44, doi: 10.3390/wevj9030044.

[29] C. Srithapon, P. Ghosh, A. Siritaratiwat, R. Chatthaworn, "Optimization of Electric Vehicle Charging Scheduling in Urban Village Networks Considering Energy Arbitrage and Distribution Cost," Energies, vol. 13, no. 2, 2020, Art. no. 349, doi: 10.3390/en13020349.

[30] C. Marmaras, E. Xydas, L. Cipcigan, "Simulation of electric vehicle driver behavior in road transport and electric power networks," Transportation Research Part C: Emerging Technologies, vol. 80, pp. 239-256, 2017, doi: 10.1016/j.trc.2017.05.004.

[31] Bundesverbands der Energie- und Wasserwirtschaft e.V. (BDEW), "Standardlastprofile," BDEW, 2017.

\section{BIOGRAPHIES OF AUTHORS}

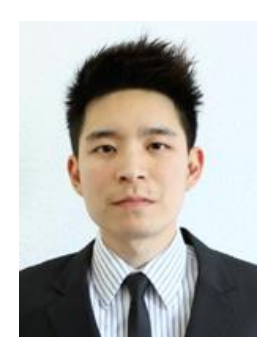

Paramet Wirasanti, he received the B.Eng. degree in Electrical Engineering from Chiang Mai University, Thailand, in 2003, the M.S. degree in Mechatronic from Leibniz University Hannover, Hannover, Germany, in 2008, and Ph.D. degree in Electrical Engineering from South Westphalia University of Applied Sciences, Soest, Germany collaboration with University of Bolton, UK, in 2014. Currently, he is a lecturer at Department of Electrical Engineering, Chiang Mai University, Thailand. His research interests are in the areas of automated control function in distribution power supply systems and power systems management. 


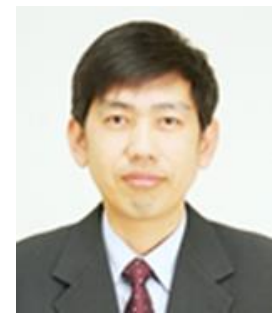

Suttichai Premrudeepreechacharn, he received the B.Eng. degree in Electrical Engineering from Chiang Mai University, Chiang Mai, Thailand, in 1988 and the M.S. and Ph.D. degrees in electric power engineering from Rensselaer Polytechnic Institute, Troy, NY, USA, in 1992 and 1997, respectively. Currently, he is an Associate Professor at the Department of Electrical Engineering, Chiang Mai University. His research interests include micro grid system, power system protection, power system analysis, and power system planning. 